\title{
Síndrome da cauda flácida em cão da raça Labrador Retriever - Primeiro relato no Brasil
}

\author{
Limber syndrome in a Labrador Retriever dog - \\ First report in Brazil
}

\author{
Maria Lígia Mistieri $^{1}$ Vera Grevel $^{2}$ João Guilherme Padilha Filho ${ }^{3}$ \\ João Paulo da Pascon ${ }^{4}$ Júlio Carlos Canola ${ }^{3}$ Daniel Orlato ${ }^{1}$ \\ Marileda Bonafim de Carvalho ${ }^{3}$
} \begin{abstract}
A síndrome da cauda flácida é uma enfermidade
que acomete cães de caça, principalmente Labradores Retriever
e do grupo Pointer. Embora sua etiologia não esteja totalmente
definida, sabe-se que sua ocorrência é precedida de esforço
físico extenuante, exposição ao frio ou água fria e confinamento
em caixas de transporte. O presente trabalho descreve o caso
de um cão da raça Labrador Retriever, macho não castrado,
de quatro anos de idade que apresentou súbita dor e flacidez
da cauda após banho frio. Fratura vertebral, síndrome da
cauda eqüina, outras enfermidades da medula espinhal ou de
glândulas adanais e afecções prostáticas foram descartadas
após exames auxiliares. A divulgação deste relato é relevante
uma vez que esta síndrome ainda não foi descrita no Brasil. RESUMO

Palavras-chave: injúria do músculo coccígeo, "cauda fria”, "cauda congelada”, ”cauda flácida”.
\end{abstract}

\section{ABSTRACT}

Limber syndrome is a disease that occurs in hunting dogs, commonly Labrador retriever and in dogs that belong to the group of Pointer. The aetiology is still unknown, but its occurrence is prior to extenuating exercises, cold exposure and cold water and transport jail maintenance. This article describes the case of a 4-year-old-intact-male Labrador Retriever that suddenly developed tail pain and limberness after cold bath. It was possible to exclude vertebral fracture, cauda equina syndrome, spinal cord or adanal gland injuries and prostatic disease as the auxiliary evaluations were made. This publication is important because there are no reports of Limber syndrome in Brazil.

Key words: coccygeal muscle injury, cold tail, frozen tail, limber syndrome.

A condição referida como síndrome da cauda flácida é bem conhecida por pessoas que trabalham com cães de caça, principalmente do grupo Pointer e da raça Labrador Retriever. O caso típico consiste de um cão saudável adulto que subitamente desenvolve flacidez de cauda e dor à palpação da área situada a 8$10 \mathrm{~cm}$ à inserção da mesma. Os cães afetados do grupo Pointer geralmente apresentam histórico de transporte prolongado em gaiola, trabalho extenuante no dia anterior ou exposição ao frio ou umidade, seja esta última por prática de natação ou banhos. A condição desaparece em poucos dias, com ou sem a administração de antiinflamatórios, e menos da metade dos animais acometidos apresentam reincidência da afecção (HEWISON, 1997; STEISS et al., 1999; GREVEL, 2004).

\footnotetext{
${ }^{1}$ Programa de Pós-graduação em Cirurgia Veterinária, Faculdade de Ciências Agrárias e Veterinárias (FCAV), Universidade Estadual Paulista (UNESP), Via de Acesso Paulo Donatto Castelane, s/nº, 14870-000 Jaboticabal, SP, Brasil. E - mail: malimistieri@yahoo.com.br. Autor para correspondência

${ }^{2}$ Policlínica de Pequenos Animais, Universidade de Leipzig, An den Tierkliniken, 1723, 04103, Leipzig, Alemanha

${ }^{3}$ Departamento de Clínica e Cirurgia Veterinária, FCAV, UNESP, Via de Acesso Paulo Donatto Castelane, s/nº, 14870-000 Jaboticabal, SP, Brasil

${ }^{4}$ Programa de Pós-graduação em Medicina Veterinária, FCAV, UNESP, Via de Acesso Paulo Donatto Castelane, s/nº $14870-000$ Jaboticabal, SP, Brasil
} 
Não se sabe ao certo a etiologia desta afecção, supondo-se que decorra de tendinite ou miosite de músculos da região sacro-coccígea (WILKINS, 1997). Este relato tem por objetivo descrever a ocorrência desta referida sindrome em um cão da raça Labrador Retriever, macho não castrado, de quatro anos de idade e divulgar a ocorrência da mesma no Brasil, visto que até o presente momento, sua incidência era restrita apenas à países de clima frio.

Um cão da raça Labrador Retriever, macho, não castrado, de quatro anos de idade apresentou flacidez súbita da cauda, com dor à manipulação da mesma, dor ao sentar e apatia. $\mathrm{O}$ animal foi atendido no Hospital Veterinário "Governador Laudo Natel”, da Universidade Estadual Paulista (UNESP), Campus de Jaboticabal, com suspeita de traumatismo. Foi realizada avaliação radiográfica em busca de evidências de síndrome da cauda eqüina, fratura ou luxação lombosacra ou sacro-coccígea, uma vez que o animal não permitia exame clínico minucioso, mesmo após sedação, devido à dor localizada na região proximal à inserção da cauda. Não foi verificada nenhuma alteração radiográfica que denotasse quaisquer das condições anteriores; da mesma forma, o exame neurológico revelou-se normal. O animal foi submetido a hemograma, urinálise, espermograma e ultra-sonografia abdominal em busca de alterações prostáticas, mas nenhuma alteração consistente foi encontrada. No dia seguinte, durante nova anamnese, o proprietário recordou-se que o cão havia sido banhado com água fria no dia anterior e que já havia apresentado quadro bastante semelhante, porém menos intenso, dois anos antes, também após banho frio.

$\mathrm{O}$ animal foi medicado com meloxicam $\left(0,1 \mathrm{mgkg}^{-1}\right.$, por via oral, uma vez ao dia) e o proprietário foi instruído a observá-lo. Foi obtida melhora completa do quadro após a primeira e única dose da medicação.

Poucos casos semelhantes estão descritos na literatura, no entanto, os animais acometidos são provenientes de ambientes frios e nenhum relato foi encontrado no Brasil.

De acordo com STEISS et. al. (1999) e GREVEL (2004), os cães, em sua maioria, recuperam-se espontaneamente, dentro de três a dez dias e alguns apresentam acentuada melhora após administração de anti-inflamatórios. Os mesmos autores sugerem que diagnósticos incorretos como fraturas, enfermidade da medula espinhal ou de glândulas adanais e até mesmo doença prostática são freqüentes, principalmente em regiões nas quais esta afecção não é muito conhecida.

A confirmação da suspeita é possível após exclusão das outras possibilidades já citadas; dosagem da creatina cinase, que se mostrará discretamente elevada logo após o aparecimento dos sinais clínicos; avaliação eletromiográfica, que revelará impulsos espontâneos anormais restritos à musculatura coccígea, mesmo alguns dias após o início do quadro; além de evidências de injúria às fibras musculares ao exame histopatológico (STEISS, 2002). Embora nenhum destes exames auxiliares tenha sido realizado, o diagnóstico provável baseou-se na anamnese, predisposição racial, evolução clínica e exclusão dos diagnósticos diferenciais.

Faz-se relevante a divulgação deste caso para que a síndrome da cauda flácida se torne mais conhecida no Brasil e possa ser incluída, como diagnóstico diferencial, em quadros de dor na base da cauda e flacidez da mesma, especialmente em cães de raças com aptidão para caça.

\section{INFORME VERBAL}

GREVEL, V. 2004. Klinik für Kleintiere. An den Tierkliniken, 23, Leipzig Universität, Leipzig Alemanha.

\section{REFERÊNCIAS}

HEWISON, C. Frozen tail or limber tail in working dogs. Vet Rec, v.140, n.20, p.536, 1997.

STEISS, J. et al. Coccygeal muscle injury in English Pointers (limber tail). J Vet Intern Med, v.13, n.6, p.540-548, 1999.

STEISS JE. Muscle disorders and rehabilitation in canine athletes. Vet Clin North Am: Small Anim Pract v.32, n.1, p.267285, 2002 .

WILKINS, C.M. Frozen tail or limber tail in working dogs. Vet Rec, v.140, n.22, p.588, 1997. 